\title{
The Limits to Participatory Planning: A Reply to Adaman and Devine
}

\author{
Geoffrey M. Hodgson
}

11 February 2004

To be published in Economy and Society

The Business School, University of Hertfordshire, De Havilland Campus, Hatfield, Hertfordshire AL10 9AB, UK

www.herts.ac.uk/business www.geoffrey-hodgson.ws

Address for correspondence:

Malting House, 1 Burton End, West Wickham, Cambridgeshire CB1 6SD, UK

g.m.hodgson@herts.ac.uk

Keywords: socialism; planning; markets; tacit knowledge; innovation, autonomy

\begin{abstract}
Fikret Adaman and Pat Devine (2001) responded to an article in which I criticized proposals by socialists to give markets marginal role (Hodgson, 1998). This present essay continues the debate, raises some additional issues and considers some later works by Adaman and Devine. A central problem in any economic system is the existence of conflicting plans, and some partial use of the market is required to deal with this problem. In particular, the Adaman and Devine proposal for participatory planning lacks clear and operational criteria to distinguish those cases where (according to them) markets should, and should not, be deployed. Their reference to the $\mathrm{M}$-form firm does not help them in this regard. This reply further considers the inadequate treatment of tacit knowledge and innovation in that proposal. Their proposal also has the serious weakness that it allows little separation of powers and requires all but the most trivial of decisions to be submitted to an all-encompassing, unitary system of decisionmaking. Legitimate individual or group autonomy is thereby endangered.
\end{abstract}




\title{
The Limits to Participatory Planning: A Reply to Adaman and Devine
}

\author{
Geoffrey M. Hodgson
}

Several years ago, Pat Devine (1988) proposed a model of a socialist economy involving democratic participatory planning. This was later developed with Fikret Adaman in several joint works (Adaman and Devine, 1996, 1997, 2002). This was a very welcome effort, as attempts by socialists to lay out in detail how socialism actually might work in practice including how economic decisions of production and allocation are made - are very rare. However, I took the view that the proposals by Adaman and Devine were insufficiently clear in operational terms, based on a faulty understanding of the role of tacit knowledge in the economy, and would stifle innovation (Hodgson, 1998, 1999). More recently, Adaman and Devine (2001) have responded to my arguments. Here I take the opportunity to continue the debate. I do not respond to all of their points, but choose those that relate most closely to the central issue of the viability of their proposal.

The first section below raises the general problem of conflicting plans. The second and third sections concern the vagueness of the Adaman-Devine criteria for distinguishing between 'market exchange' and 'market forces' and thereby the conditions (according to them) under which participatory planning would apply. The fourth section raises the related problem of who would have the right to participate in decision-making. The fifth and sixth sections revisit the questions of tacit knowledge and innovation respectively. In each case I show that their response is inadequate. I conclude that the Adaman-Devine proposals are unclear in conception, and in practice would endanger legitimate individual or group autonomy.

\section{Plans and planning}

Within any socio-economic system, a central problem is the reconciliation of conflicting preferences or plans. One solution is to impose a dictatorship, where a leading body decides 
which plans are to be adopted and overrides the wishes of the dissenters. Another solution is to establish some democratic voting system, which after deliberation may still block the plans of a minority. A third option is to use a system of commodity exchange and the price mechanism. In reality, different structured combinations of all three mechanisms are found in many societies. No mechanism is itself without its demerits. Adaman and Devine (2001: 230) propose that major decisions should be subjected to a process of participatory and democratic planning, and they confine commodity exchange or the market mechanism to 'the sale and purchase of output of existing capacity'.

Personally I am sympathetic to proposals for a degree of participatory democracy. But we must be realistic: is it possible to confine the market to a lesser role, in the manner proposed? Any response to this question must take into account one of the advantages of the market, alongside its disadvantages. Any democratically planned system has to reconcile key differences, before agreement and action are possible. Such conflicts have to be resolved before any plan can be formulated in detail. In contrast, in a market system, many piecemeal agreements and actions are possible, without concurrence on everything. Negotiation over price is often a relatively flexible mechanism by which some conflicts can be ameliorated. 'Separate, diverse plans can be reconciled by multiple, bilateral deals of negotiated exchange' (Hodgson, 1998: 408). In this way, and perhaps most importantly, the market to a significant degree can allow for multiple centres of decision-making, without the requirement that all plans are submitted to a single system of authority.

However, Adaman and Devine (2001: 231) bypass this crucial argument to characterize my position in the following terms: 'Hodgson seems to conceive of planning as an aggregation problem in which pre-existing plans have to be reconciled, either by dictatorial imposition or by majority decision. ${ }^{2}$ In response, I do not conceive it as such, and their reply misses the point. I have never believed that planning (of any sort) is an aggregation process, merely rendering consistent such pre-existing plans. It is important that people can be sometimes persuaded to change their goals. My argument in the preceding paragraph does not depend on whether plans are pre-existing and unchanging, or change during some process of interaction or negotiation. What it recognizes is that plans are likely to conflict, whether or not they have changed in the past, or are changing, or will change in the future.

The existence of conflicting plans is an endemic problem, and it would be a dangerous mistake to assume that any system of participatory or democratic planning will at some point 
always remove these conflicts. Adaman and Devine (2002: 350) 'favour consensual decisionmaking' but 'if agreement cannot be reached, then decisions would be made through an agreed formal voting procedure.' Thereby the majority can outvote any minority. A danger in their proposal is thus that diversity and legitimate autonomy may be undermined. In some cases the majority may have the moral basis for its rule. But unqualified majority rule has dangers too, both in ethical and innovative terms.

\section{How can we distinguish between 'market exchange' and 'market forces'?}

However, even if majority rule was generally justifiable, the Adaman-Devine proposal for a democratic system of participatory planning is both vague and unworkable, as I shall explain. Crucially, their attempt to distinguish between 'market exchange' and 'market forces' is conceptually vague and non-operational in practice. According to Adaman and Devine (2001: 230):

A distinction is drawn between market exchange, involving the sale and purchase of output of existing capacity, and market forces, which in capitalist economies bring about changes in the structure of capacity through atomistic decisions on investment that are co-ordinated ex post. Market exchange remains an integral part of our model but market forces are replaced by a process of negotiated co-ordination in which the groups principally affected co-ordinate decisions on investment and disinvestments ex ante.

Elsewhere, I criticize this attempted distinction at length (Hodgson, 1998: 413-15; 1999: 4345). A key argument is that no economic system is static, and products, processes, tastes and knowledge are continuously changing. 'Accordingly, it would be difficult to avoid the conclusion that every decision should be referred to some 'negotiated coordination body' because to some extent it involved something new' (Hodgson, 1998: 415). To make the Adaman-Devine distinction operational, two things are required: first, a clear set of rules to distinguish in practice between 'market exchange, involving ... existing capacity' and 'market forces' involving 'changes in the structure of capacity'; and second, clear proposals as to how these rules may be policed in practice, to prevent people illegally resorting to the market in the cases when (according to Adaman and Devine) their activities should be subjected to 'negotiated co-ordination' on some democratic committee. 
Adaman and Devine fail on both these counts, and I shall elaborate on the inadequacy of their criteria below. In response to my challenge they propose that similar demarcatory criteria are actually in operation within modern capitalism. They point to the 'multi-divisional form of firm organization'. In these firms, according to Adaman and Devine (2001: 231-2):

the headquarters establishes divisions, receives their profits, monitors their performance and decides whether they should be expanded, contracted or closed and whether new divisions should be established. Although the divisions may have a decentralized budget for minor investment, the headquarters acts as an internal capital market and is responsible for major investment and disinvestments. ... Thus, the M-firm may be thought of as institutionalising the distinction between market exchange and market forces.

Note that Adaman and Devine make explicit neither the clear rules nor the demarcation criteria; they simply claim that the distinction has been operationalized in practice within Mform capitalist corporations. Even if their observation were accurate, it is not adequate. A request for detailed criteria is not answered simply by pointing to a domain where such criteria are allegedly operationalized.

In addition, and unfortunately for Adaman and Devine, their empirical claim is inaccurate, in at least two respects. First, the M-form firm does not involve a 'corporate structure in which the divisions engage in market exchange' (Adaman and Devine, 2002: $346 \mathrm{n}$.). In the M-form corporation it is the 'legal person' of the corporation (not its divisions) that holds property rights and can exchange products on the market. Divisions may transfer goods or services internally with the firm and keep their own accounts, but this does not involve the transfer of property rights and thus it is not exchange proper. I have made this argument at length elsewhere, so the details will not be repeated here (Hodgson, 2002). Adaman and Devine follow the regrettable practice of some mainstream economists in obfuscating the legal nature of the firm and its property rights, and seeing 'markets' in places that - by sensible definition - they do not exist.

Second, the evidence does not suggest that M-form firms have successfully operationalized a distinction between strategic and major investment at the centre and tactical and minor investment in the divisions. In reality, operationalizing the distinction between the rights of corporate divisions and the corporate centre has been a continuous and unresolved source of tension within prominent M-form firms. Robert Freeland (1996a, 1996b, 2001) shows that 
historically there has been a problem of demarcating the powers and responsibilities of the divisions and the centre with the M-form firm. ${ }^{3}$

Focusing on the experience in General Motors (GM) - widely cited as the archetypical Mform firm - Freeland (1996a: 492) shows that the 'textbook image of GM's M-form firm is a

myth' ${ }^{4}$ Contrary to the idea that the corporate headquarters dealt with strategic issues, devolving tactical issues to the divisions, GM's history shows episodes where decentralization was introduced, not along the lines suggested by Adaman and Devine, but

to create divisional consent to corporate policies. During other periods, it reverted to administrative centralization in which the general office made both strategic and operating decisions. (ibid.)

Hence the reality of the classic M-form firm points not to a clear-cut distinction between central and divisional responsibilities, but to a centralized manipulation of the divisional structure. Adaman and Devine rely on what Freeland calls a 'mythical' account of the M-form firm to sustain a distinction for which there is no evidence of practical operationalization.

A crucial difference between the M-form firm in reality, on the one hand, and the proposal by Adaman and Devine, on the other other, is that the former involves multiple centres of power, each implementing its own criteria to separate the powers of the divisions and the centre, whereas the latter depends on a single set of (unclear) criteria devised by Adaman and Devine themselves. Hence, in the case of the M-form firm, the different sets of demarcation criteria are to some extent tested by the performance of the firm itself, and its capacity to survive in the market. No such test or corrective exists in the Adaman-Devine proposal. If the demarcation criteria place excessive limits on the right to enforce decisions without resort to the hierarchy of committees, then there is no obvious power or mechanism to correct any bureaucratic excess. This is a serious limitation to the Adaman-Devine proposal and does not apply to the M-form firm.

\section{Some Illustrations}

To show the weaknesses of the Adaman-Devine demarcation criteria, consider the following illustrations. In each case I ask Adaman and Devine whether 'market exchange' or 'market forces' are involved. Upon the answer to this question depends whether the decision can be 
made and enforced autonomously, or would require referral to the hierarchy of participatory committees.

1. A lathe in an engineering works requires replacement. An identical model of lathe is unavailable. Instead there is an improved model, which introduces a new electronic control mechanism. But in most other respects the old and the new lathes are similar. If the old lathe is replaced by the new one, is this merely a case of 'existing capacity' or does it constitute 'investment and disinvestment'?

2. A firm integrated under one management has two plants, in different locations. The management propose to remove some activities from one plant and locate them in the other. In other respects the output of the firm as a whole is unchanged. Is this a merely case of 'existing capacity' or does it amount more substantially to changes in 'the pattern of investment, in the structure of productive capacity, ... in the geographical distribution of economic activity, [or] in the size ... of individual production units' (Devine, 1988: 23)? Or does it depend on the distance between the two plants, or on whether some workers are displaced from one plant to the other, or on the scale of the activities being relocated? If so, then by how much?

3. A couple wish to make internal changes to their home, which they own privately. They propose to make a study for one partner, who often brings work home from her office. With the agreement of her colleagues, she will work at home for up to two days a week, using a newly purchased computer. Do these changes involve 'investment' or a change 'in the geographical distribution of economic activity'?

4. An office worker discovers a way of simplifying and improving a record-keeping system, by removing some redundant information and recategorizing some of the items. Must this innovation be referred to the relevant committees, or can it be implemented simply by agreement with immediate and affected colleagues? Or it does it matter that the information concerned is of sensitivity or importance? And who is to know whether the removed information is really redundant?

Adaman and Devine provide inadequate criteria to answer these questions. Yet, to repeat, in each case the answer is crucial to determine whether, according to them, agents can act on their own (including the option of buying or selling), or must instead refer the proposed change to a hierarchy of democratic committees. According to their criteria as they stand, it would seem that in all the above cases 'market forces' apply, and the proposal will be 
required for referral to the committees. Consequently, in the absence of sharp criteria, there is nothing to stop almost every economic activity being referred to the participatory bureaucracy.

Consider case (1) above. According to the Adaman-Devine criteria, it would have to be referred to the committees, because new investment is involved, which otherwise would mean the use of 'market forces' (in their terms). This would be the case even if the change in the lathe amounts to simply the replacement (and slight improvement) of one component. The operational vagueness of their criteria means that they can claim to retain a place for market exchange but in practice put almost everything outside its reach. The bureaucracy reaches almost everywhere, with its legitimacy based on the claim that everyone affected can participate; but the extent of its operational terms of reference implies a burden of attendance at meetings that few would relish.

My purpose here is not to defend any arrangements in existing society, but to uphold that the Adaman-Devine distinction between 'market exchange' and 'market forces' is both conceptually unclear and lacks sharp, practical, operational rules. Consequently their proposal embodies the danger that the committees will claim near-universal authority, and a gargantuan participatory bureaucracy will swallow up all economic activity.

\section{Who participates?}

At this stage I wish to raise another problem. According to Adaman and Devine (2001: 234): 'Our general proposal is that, at each level of decision making, those who are affected by the decisions participate in making them.' And again: 'all those with either a relevant input or a legitimate interest in the outcome, i.e. all those who are affected by the activity' will participate (Adaman and Devine, 2002: 345).

The ominous problem arises as to who is allowed and who is disallowed to participate. If the decision were up to every individual, then committees may be overly dominated by snoopers, committee-lovers, careerists or busy-bodies. Consider case (3) above. Has any neighbour the right to participate in the decision to invest in a home office and home computer on the grounds that their user will now park their car on the road outside, for up to two additional days a week? Surely not. Yet the neighbour would be genuinely 'affected' by the decision to stay at home and park the car outside. 
Consider another example, more remote from the world of industry and employment. Do 'right to life' campaigners have the right to interfere in abortions, on the grounds that their strong feelings and beliefs are violated by the killing of a foetus? Here, as elsewhere, legislatures place limits on the right of interference, no matter how strongly that others may feel that they are affected by such actions. I suggest that here, as elsewhere, the right to participate in decision-making should be limited. A woman's right to choose comes into conflict with a universal principle of participation.

Just as acutely, what of the decision to procreate? Everyone on Earth is affected by the alarming growth of the human population in the face of limited material resources. Hence does everyone have the right to interfere in every decision to copulate without contraception? Of course not. It would be an intolerable intrusion into private intimacy, notwithstanding the possible consequence of an additional human being in an overcrowded world.

Some people object to their neighbours mowing the lawn on Sundays, preferring at least one day a week of peace and quiet. Others object to high trees or hedges that block out their light. In some of these cases rights of interference may be established, in others not. In any case, it would be intolerable of the right of interference were unlimited, to the degree they applied to any claim of being affected by the decision. In practice, what happens in existing developed societies is that complicated rules concerning rights and responsibilities in all such decisions have evolved over time, through a combination of common and statute law.

I do not suggest that Adaman and Devine should attempt to specify all such rules that would operate in their desired socialist society. To respond adequately to such a request would involve enormously detailed specifications. Instead they should admit that (a) their distinction between 'market exchange' and 'market forces' does not work in conceptual and practical terms, (b) any rule system specifying and demarcating rights and responsibilities would require the piecemeal accumulation over time of case law and statutory measures, and (c) in the end their proposal for participatory planning cannot effectively and entirely confine the market to 'existing capacity'.

\section{Tacit knowledge}

Previously I criticized Adaman and Devine for misunderstanding the nature of tacit knowledge. In earlier works they repeatedly claimed that 'tacit knowledge is discovered and 
articulated and, on the basis of that knowledge, economic decisions are consciously planned and coordinated' (Adaman and Devine, 1996: 531-2) and 'a process of cooperation and negotiation ... would enable tacit knowledge to be articulated' (Adaman and Devine, 1997: 75). These statements misunderstand tacit knowledge because, by its nature, it can neither be fully discovered nor articulated. In their response to my critique of their conception of tacit knowledge they ignore the vital argument that it cannot be articulated. Furthermore, the mistaken notion that tacit knowledge can be 'mobilised and articulated' is later repeated (Adaman and Devine, 2002: 343).

Adaman and Devine (2001: 230) refer to committees 'using' or 'having available' tacit knowledge and of processes that enable 'the tacit knowledge of the participating groups to inform the decisions made'. In a sense, we all make use of tacit knowledge and these statements can be interpreted in an unobjectionable manner. But when we make use of this knowledge, it is crucially and by definition neither articulated nor made conscious. Hence committees cannot 'use' tacit knowledge in the sense of laying it out explicitly for discussion. For this reason their statements are ambiguous and potentially misleading.

The following statement by Adaman and Devine (2001: 234) is also problematic: 'The decision-making bodies would have available to them two sorts of knowledge: explicit, 'objective', frequently quantitative; and implicit, 'subjective', tacit, typically qualitative, provided by the contributions of the groups taking part in the process.' This passage confuses the distinction between explicit and tacit knowledge with two other very different distinctions, namely between objective and subjective, and between quantitative and qualitative. Neither of the other two distinctions have any close relationship to the distinction between explicit and tacit knowledge. Adaman and Devine do not define the terms 'objective' or 'subjective' but by most understandings of these terms they do not relate to the explicit-tacit dichotomy. The danger here is that Adaman and Devine mistakenly conflate the tacit with the 'subjective' or 'qualitative'.

For example, if I say: 'I believe that there are several beautiful fairies at the bottom of my garden' is this statement 'subjective' and 'qualitative'? Perhaps so. But in any case, the statement is certainly not tacit. It is explicit and false.

Essentially, while conceding the importance of tacit knowledge, Adaman and Devine are extremely vague concerning its nature and use. Furthermore, neither do they correct the proposal in their preceding statements that tacit knowledge can be 'articulated', nor do they 
recognize that attempts to fully articulate tacit knowledge would be time-wasting and ultimately destructive. As Michael Polanyi (1967: 18-19) put it: 'an unbridled lucidity can destroy our understanding of complex matters ... the ideal of eliminating all personal elements of knowledge would, in effect, aim at the destruction of all knowledge.'

Overall, Adaman and Devine fail to appreciate that the importance, inevitability and irreducibility of tacit knowledge in any society places severe limits on explicit, deliberative planning of any kind. In response to this argument I am accused of 'irrationalism and institutional determinism' (Adaman and Devine, 2001: 236), without any definition of these terms. In response, I do not argue in favour of 'irrationalism'. Instead I propose that rational deliberation has cognitive, informational and practical limits. In this respect I can claim support from a wide range of theorists, from Thorstein Veblen to Herbert Simon. Furthermore, as Polanyi (1967) argued beautifully in his classic book, rationality itself depends on the knowledge that is unavoidably tacit and inexplicit. Following Veblen and others, I also argue that institutions are carriers of knowledge. But I strongly reject the view that individual aims or activity are entirely determined by institutions. ${ }^{5}$

\section{Innovation and Entrepreneurship}

Hodgson (1998) argued that the system proposed by Adaman and Devine would often stifle innovations by requiring them to be approved by a network of committees. The essential point here is that much successful innovation depends on the intuitions of a minority, which is often unable to persuade the majority due to the nature of innovation itself. Most people tend to prefer the tested and the familiar. Adaman and Devine $(2001,2002)$ duck this argument to propose instead a unitary system of decision-making in which the majority always rules. There is no denying that majorities can sometimes innovate, as Adaman and Devine (2002) explore at some length, but they simply ignore the implications of their proposed curtailment of innovations that do not obtain majority approval.

There is a high likelihood of error here. For example, when the first electronic computer was developed in Manchester in the 1940s, it was thought by a majority of experts to be so powerful that only one model would be required in the whole country. No-one fully appreciated the possible uses of the computer beyond a mere calculator, and as a processor of vast amounts of non-numeric as well as numeric information. There is no obvious reason why a more participatory decision-making system would have had a different opinion at that time. 
Essentially, many technological and institutional innovations depend on the promotion of a minority view that is not widely supported or acknowledged at the outset.

Hence another advantage of a market system is that, within limits and with its own defects, it does offer some scope for inventors or entrepreneurs with new ideas - which are inevitably regarded by some as doomed or strange - to seek a market for their innovations and to benefit from any success. This has always been an important explanation for the technological dynamism of capitalism, and it has frequently been raised in the socialist calculation debate as a serious limitation comprehensive central planning. This point remains important, even if some innovation is possible within other organizational structures, and may be motivated other than by profit.

The response of Adaman and Devine (2001: 235) to this argument is somewhat surprising and symptomatic. They admit that innovation was discussed 'only briefly' in Devine (1988) and 'it is only in ... more recent work' that it is developed more fully. ${ }^{6} \mathrm{I}$ ask the reader to reflect upon this admission: a major attempt to establish the workings of a planned economy, that has attracted some support on the left, admittedly addressed the central topic of innovation 'only briefly' and more than a decade passed before sufficient attention was by admission devoted to this topic. The history of socialism is full of proposals that are high in sentiment and morality but low in operational detail. Sadly, despite its rare and commendable attempt to consider actual economic mechanisms of decision-making, the Adaman-Devine proposal fails to avoid the same criticism.

According to the Adaman-Devine proposal, innovation cannot be allowed free access to the market. Any proposed innovation must be considered by the committees. Adaman and Devine (2001: 235) try to deal with the problem of uncertainty of success by decreeing that the committees must entertain a multiplicity and 'variety' of innovations with a 'pluralistic set of criteria'. After due experimentation and testing the superior and more socially useful innovations will be chosen: 'the criteria and interests involved in selecting across the innovations that emerge will determine the outcome of the innovation process.'

What they fail to show is how it is ensured that a sufficient variety of innovations will be chosen within a 'single participatory process' (Adaman and Devine, 2002: 352) with a sufficiently 'pluralistic set of criteria'. Even the history of capitalism is littered with inventions that failed, or nearly failed, to get the backing of financiers or sponsors, even when many such independent bodies were approached. The requirement of committee approval, 
within a unitary rather than a polycentric system of committees, would make the chances worse, not better.

\section{Conclusion}

One of the biggest weaknesses in the Adaman-Devine proposal is that provides little separation of powers, except at the periphery of decision-making, and even here any autonomy at the periphery is inadequately demarcated and protected. It proposes participation, but in its name it requires submission and interference, in regard to all but at best the most trivial of economic decisions.

To this weakness, which has been characteristic of socialism since the inception of that term in the 1830s (Hodgson, 1999), their proposal adds another. Instead of autonomy it heralds a life of participation on committees. Furthermore, the limits of committee interference in decision-making at every level of society are not clearly laid down. The proposal that everyone has the right to participate in committees that affect them does not solve the problem of practically unlimited committee power. If everyone must spend much of his or her time running round from meeting to meeting, then genuine and fruitful participation is diminished.

In practice, the Adaman-Devine proposal would end up as a monstrous apparatus of unlimited interference and endless deliberation. Its unitary structure of interlocking committees lacks an effective separation and plurality of powers. To rectify these omissions, people must have the right to make several important decisions concerning their lives and their property themselves, subject to some reasonable laws and constraints. Within broad limits, people have the right to autonomy and privacy, and to be protected to a large degree from the interference of individuals or committees, even if the latter may claim that they are affected by actions within this zone of self-rule. This also means retaining within broad limits all legitimate rights to buy and sell property - and retaining a substantial economic role for the market. Socialist doctrine has no chance whatsoever of survival unless it fully accepts and adjusts to this fact. ${ }^{7}$ 


\section{References}

Adaman, Fikret and Devine, Pat (1996) 'The Economic Calculation Debate: Lessons for Socialists', Cambridge Journal of Economics, 20(5), September, pp. 523-37.

Adaman, Fikret and Devine, Pat (1997) 'On the Economic Theory of Socialism', New Left Review, no. 221, January-February, pp. 54-80.

Adaman, Fikret and Devine, Pat (2001) 'Participatory Planning as a Deliberative Democratic Process: A Response to Hodgson's Critique', Economy and Society, 30(2), May, pp. 22939.

Adaman, Fikret and Devine, Patrick (2002) 'A Reconsideration of the Theory of Entrepreneurship: a Participatory Approach', Review of Political Economy, 14(3), July, pp. 329-55.

Chandler, Alfred D., Jr (1962) Strategy and Structure: Chapters in the History of the Industrial Enterprise (New York: Doubleday).

Devine, Pat (1988) Democracy and Economic Planning: The Political Economy of a SelfGoverning Society (Cambridge: Polity Press).

Devine, Patrick (2002) ‘The Institutional Context of Entrepreneurial Activity', in Adaman, Fikret and Devine, Patrick (eds) (2002) Economy and Society: Money, Capitalism and Transition (Montreal: Black Rose Books), pp. 440-54.

Fligstein, Neil (1990) The Transformation of Corporate Control (Cambridge, MA: Harvard University Press).

Freeland, Robert F. (1996a) 'The Myth of the M-Form? Governance, Consent, and Organizational Change', American Journal of Sociology, 102(2), September, pp. 483-526.

Freeland, Robert F. (1996b) 'Theoretical Logic and Predictive Specificity: Reply to Shanley', American Journal of Sociology, 102(2), September, pp. 537-542.

Freeland, Robert F. (2001) The Struggle for Control of the Modern Corporation:

Organizational Change at General Motors, 1924-1970 (Cambridge and New York:

Cambridge University Press).

Hodgson, Geoffrey M. (1998) 'Socialism Against Markets? A Critique of Two Recent Proposals', Economy and Society, 27(4), November, pp. 450-76.

Hodgson, Geoffrey M. (1999) Economics and Utopia: Why the Learning Economy is not the End of History (London and New York: Routledge). 
Hodgson, Geoffrey M. (2002) 'The Legal Nature of the Firm and the Myth of the FirmMarket Hybrid', International Journal of the Economics of Business, 9(1), February, pp. $37-60$.

Hodgson, Geoffrey M. (2004) The Evolution of Institutional Economics: Agency, Structure and Darwinism in American Institutionalism (London and New York: Routledge).

Polanyi, Michael (1967) The Tacit Dimension (London: Routledge and Kegan Paul).

Shanley, Mark (1996) 'Straw Men and M-Form Myths: Comment on Freeland', American Journal of Sociology, 102(2), September, pp. 527-536.

Williamson, Oliver E. (1975) Markets and Hierarchies: Analysis and Anti-Trust Implications: A Study in the Economics of Internal Organization (New York: Free Press). 


\section{Endnotes}

${ }^{1}$ The problem of maintaining autonomy and diversity is an important theme in Hodgson (1999). Adaman and Devine (2001, 2002) and Devine (2002) make no reference to this book.

${ }^{2}$ The five instances where Adaman and Devine use the phrases 'Hodgson seems' to say soand-so or 'Hodgson appears to believe' are followed neither by an accurate characterization of my personal view nor of my written position. But I do not wish to bore the reader with excessive details.

${ }^{3}$ Freeland (1996b) is effective response to Shanley's (1996) critique of Freeland (1996a). A fuller account is in Freeland (2001).

${ }^{4}$ General Motors was one of the four main studies in Chandler (1962). Chandler's picture of a multidivisional structure, with a strategic centre dealing with long-term planning, while devolving more mundane matters to the divisions, was taken up by Williamson (1975). Fligstein (1990) and Freeland (1996a, 2001) are both critics of Chandler's account of the multidivisional reality and his explanation of its alleged economic efficiency.

${ }^{5}$ The limits to rationality and the role of institutions as carriers of knowledge are discussed in Hodgson (2004).

${ }^{6}$ They refer to then unpublished work that appeared later as Adaman and Devine (2002) and Devine (2002).

${ }^{7}$ Note that I am not proposing unlimited or unconstrained markets. Even capitalism prohibits the buying and selling of slaves, hard drugs, votes, and so on. Neither are rights of privacy and autonomy without limit: and rightly so. 